\title{
A CRITICAL REVIEW
}

\section{TWIN RESEARCH IN PSYCHIATRY}

\author{
BY \\ E. T. O. SLATER

\section{General Principles and Theoretical Basis}

IT is not attempted in the following review to cover the whole of the now enormous literature on twin research, even as far as it concerns psychiatry. Only works of statistical or theoretical importance will be dealt with in a critical spirit. Extensive reviews of twin literature from the general aspect are given by Newman (1923), Siemens (1924), Dahlberg (1926), von Verschuer (1927), Siemens (1932), von Verschuer (1932), Luxenburger (1932c), von Verschuer (1933), Newman, Freeman, and Holzinger (1937). Reviews of the literature as far as it specially affects psychiatry are given by Siemens (1924), Lange (1929), Luxenburger (1929, 1930 $a$ and $b, 1932 a, 1933,1935)$, and Conrad (1937). No account will be given of the now very large number of papers dealing with work on twins of purely psychological nature. It is, however, time that these works, which are of very varying merit, were submitted to critical consideration by a competent reviewer.

Twin research in psychiatry, as in other fields of human biology, is founded on a particular theory, that there are two kinds of twins, the monozygotic and the dizygotic. Both members of a pair of monozygotic twins are supposed to have exactly the same hereditary equipment. The members of a pair of dizygotic twins are supposed to be no more like each other than ordinary siblings. If this theory is correct, we are enabled to observe the results of a controlled experiment performed by nature. For if the hereditary endowment is the same, any real differences observed in monozygotic twins should be due to the environment. The differences in dizygotic twins will be due to differences both in the environment and in the hereditary equipment. This theory is probably correct (though it cannot be taken as proven), although its theoretical embryological basis has become more dubious and speculative than it seemed at first.

The distinction between monozygotic and dizygotic twins was originally based on the observation that some twins were born with separate placentæ and membranes, some with these structures in common. The latter variety were found to be always of the same sex, and as they grew up they grew in- 
creasingly like one another, so like in fact that it was often difficult to distinguish them. From a statistical point of view it was found that there was an excess number of twins born of like sex, and were one to deduct double the number of opposite-sexed twins from the total, the remaining proportion represented about the same figure as the proportion of monochorial or of similar twins. Further, it has been found that this group of similar twins, if selected on grounds of their similarity to one another in a number of characteristics commonly held to be hereditary (such as eye colour, stature, etc.), would be found to be similar in a vast number of other hereditary characteristics. A similar phenomenon would not be observed in a group of similarly chosen opposite-sexed twins. It was clear, therefore, that this group of twins formed a special group in which the hereditary constitution could be taken to be very nearly if not absolutely the same in both members of the pair. For a very long period the diagnosis of these two groups was by means of the membranes only. As, however, the placental membranes of adult twins are not easily to be rescued from the incinerator to which they have many years before been consigned and as any reliable history of the formation of those placentæ is often quite unobtainable, the method of diagnosis by similarity has gradually replaced the diagnosis by membranes, and is now to be regarded as the method of choice. For the diagnosis by membranes, even when carried out with the most exact care, can no longer be regarded as reliable. Smith (1930 and 1931) has described almost certainly uniovular dichorial twins and Curtius (1930) and Lassen (1931) have made a systematic examination of the point. Between them they examined 86 twin placentæ by macroscopical, microscopical, and Roentgenological methods, and carried out a very careful anthropological investigation of the like-sexed twins who could be followed up. Lassen gives their results in the following table :

\begin{tabular}{|c|c|c|c|c|c|c|c|}
\hline & & \multirow{2}{*}{$\begin{array}{l}\text { NO. OF } \\
\text { CASES }\end{array}$} & \multirow{2}{*}{\multicolumn{2}{|c|}{$\begin{array}{cc}\text { PLACENTAE } \\
1 & 2\end{array}$}} & \multicolumn{2}{|c|}{ ANASTOMOSES } & \multirow{2}{*}{$\begin{array}{c}\text { SIMILARITY } \\
\text { DIAGNOSIS BY } \\
\text { ANTHROPOLOGICAL } \\
\text { METHODS }\end{array}$} \\
\hline & & & & & MACROSCOPIC & $\begin{array}{c}\text { SEEN IN } \\
\mathrm{X}-\mathrm{RAY} \text { ONLY }\end{array}$ & \\
\hline Monochorial & .. & 9 & 9 & - & 7 & 1 & Similar. \\
\hline Dichorial & .. & 21 & 16 & 5 & - & - & Opposite sex, \\
\hline ” & . & 21 & 9 & 12 & - & - & $\begin{array}{l}\text { Like sex, dis- } \\
\text { similar. }\end{array}$ \\
\hline ” & $\cdots$ & 5 & 2 & 3 & - & 1 & Similar. \\
\hline
\end{tabular}

They were unable to find any biological difference between the monochorial and the dichorial similar twins, from which it follows that the presence of one or two choria is more or less an accidental phenomenon and without much significance for the diagnosis of constitutional similarity or dissimilarity. As they found among 14 similar twins no less than five dichorial pairs, they conclude that dichorial uniovular twins are not at all uncommon; and this opinion is borne out by the fact that the percentage of monochorial twins has been per- 
sistently found to be smaller than the percentage of uniovular twins calculated from the sex distribution. Curtius (1930) considers that his results indicate that the method of diagnosis by membranes is unreliable and should be discarded. The occurrence of monochorial dizygotic twins appears to be much less common, if it occurs at all. Von Verschuer (1932a) quotes two cases of opposite-sexed monochorial twins from the literature, and has himself described (1925) a case of monochorial dizygotic same-sexed twins. The evidence for monochoria rests on the statement of an obstetrician. In view of the rarity of this phenomenon, even if it does occur, an exact diagnosis of monochoria, supported by microscopical examination, must be taken as very strong evidence of uniovularity. There is no particular difficulty from the embryological point of view in explaining the occurrence of dichorial uniovular twins, as long as the point of separation of the twin embryos is considered to be capable of occurring before the development of the chorionic anlage. Siemens (1924), who was to a large extent the author of the modern method of diagnosis by similarity, has stigmatized the diagnosis of ovularity by membranes as a petitio principii. It must, however, be pointed out that the same logical criticism applies to the diagnosis by similarity.

However, the use of the similarity method though faulty in logic is justified in fact. For though the diagnosis cannot be made a matter of certainty, it may be made with such a high degree of probability that there is no longer room for reasonable doubt. Some investigators have examined their twins with a plurality of refined methods which would be beyond the capacity of any single individual and only conveniently carried out by an anthropological institute. Such methods of reducing the chance of binovularity from one in millions to one in billions can only be necessary in exceptional cases. A case of mongolism in one only of monozygotic twins might well be examined by such elaborate methods, for instance : for so far anything approaching proof of such an event is lacking. For practical purposes, however, the diagnosis of uniovularity does not offer serious difficulties in the great majority of cases. A history of very striking similarity in appearance, supported by a short and convenient range of anthropological tests and measurements, including the very useful finger-print method, is adequate in the general run of cases. Nevertheless, it must be emphasized that the satisfactory diagnosis of ovularity is the necessary foundation of any reliable twin research, and its lack in the great majority of the earlier published cases very seriously detracts from their value. The method of diagnosis by membranes should not now be used unsupported by data from the similarity method.

At present there is little certain knowledge of the mechanism by which twins are produced. The commonly held opinion is that dissimilar twins are binovular and have arisen from the accidental production of two ova at the same time ; while similar twins are uniovular and have arisen from a single ovum by fission of the blastoderm, plural gastrulation, or by fission of the embryonic axis. In an interesting paper Curtius and von Verschuer (1932) investigated the frequency of twin-parenthood in the families of 931 twins. They came to the conclusion that there was a single recessive factor for twinning, which might 
express itself in the homozygotic state as the parenthood of twins, was transmitted and exhibited equally by the male and the female, and showed no predilection for either the monozygotic or the dizygotic type of twin. The chance of this tendency to the production of twins manifesting itself at any particular birth they calculate (after Dahlberg) as 0.06. Their paper, as well as that of Meyer (1932), which goes in a similar direction, has been subjected to a destructive criticism by Lenz (1933), who considers that the capacity of twinning must be held to be a universal human characteristic and its manifestation governed by purely environmental factors. It would seem to the reviewer that the existence of a non-universal hereditary tendency to twinning has, however, not yet been disposed of, and that the theory of a recessive inheritance which may manifest itself in the homozygotic state in the actual twin pair, a possibility which is especially suggested by Meyer's paper, has not yet received adequate consideration. As a result of Lenz's criticism von Verschuer has subsequently (1933) retreated from his former position, but he still holds to the possibility of a uniovular origin of dizygotic twins, a rather far-fetched theory put forward by himself and Curtius to explain their finding that the father could be responsible for the production of dizygotic twins. The theory briefly is that the hereditary disposition to twinning manifests itself in a splitting tendency (Spaltungstendenz), which may be exhibited by the ovum or given to it by the sperm either after or before the final maturation division. They suppose that in the last of these cases, the ovum, before it has given up the second polar body, as a result of the Spaltungstendenz given it by the spermatozoon splits off a polar body which is as large and fertilizable as the remaining fertilized ovum, and that this polar body is itself fertilized by another sperm. The result is twins of differing constitution (e.g. perhaps differing sex) but uniovular origin. The possibility of such an event occurring had already been suggested by Oluf Thompson (1929). As Thompson stated, the result of this process would be two twins of identical maternal but differing paternal heredity, and the theory might be used to explain the occurrence of very similar opposite-sexed twins. Curtius' and von Verschuer's generalization would seem to be unjustified, however, as there is no evidence that such twins exist in any number, if at all. I cannot see that in their paper the authors recognize that this peculiar variety of twin would be the necessary result of the process they suppose to take place, or that they take note of the general opinion of embryologists that in man, as in animals, the division of the primary oocyte is the reduction division, that of the secondary oocyte is an equational division. The theory is fundamentally that put forward by Dahlberg, the "Spaltungstendenz" corresponding to Dahlberg's "doubling tendency." Neither theory provides any explanation for the increasing frequency of twinning with increasing age of the mother, and all the authors are constrained to suppose that polyovulation also occurs and is independent of any hereditary factor. The theory that there is a common hereditary disposition for the production of monozygotic and dizygotic twins, a theory to which von Verschuer appears to adhere, runs counter to the finding that in Japan there is a normal uniovular-twin birth-rate but a very low dizygotictwin birth-rate. 
It is commonly assumed that similar twins are identical in respect of their hereditary equipment. This cannot by any means be taken as proven. It is an admitted theoretical possibility that in the division of the fertilized ovum there might be an unequal division of the chromosomes. Such an event has been shown to occur in the reduction division in Drosophila, resulting in individuals with more or less than their proper quota of chromosomes, or in other cases with a fragment of a chromosome being additional to the normal quota in one individual, deficient in another. There is no cogent reason why this should not also occur in the somatic division, and in man. Furthermore somatic mutations are known to occur in a variety of different organisms, and if such a mutation were to occur in one of the two cells produced by the primary fission of the fertilized ovum it would produce a true hereditary difference in the two resulting monozygotic twins. These theoretical possibilities are, however, of little practical importance : for even were they shown to occur in man, they would be events of such rarity that statistical results obtained by the examination of large numbers of twins would be little affected by them.

A more important objection to the assumption of the identical hereditary constitution of monozygotic twins has been raised, among others, by Dahlberg (1926) and Newman (1923, 1937). These authors have emphasized the importance of asymmetrical phenomena occurring in monozygotic twins, and drawn attention to the frequency of " mirror-imaging," or of discordance in respect of such characters as handedness, unilateral nævi, asymmetrical characters of finger and palm-prints, etc. Both authors suppose there is an " asymmetry mechanism," specially affecting uniovular twins, which can be productive of real differences and cannot be called environmental in nature. Newman supposes that uniovular twins are derived from the partially developed right and left halves of a single embryo, and that the degree of asymmetry reversal depends on the lateness of the time of separation of the two halves to make new individuals. It seems, however, that this reversal of asymmetry occurs, especially as regards right- and left-handedness, in fraternal as well as identical twins. The figures provided by different workers are very conflicting. From Newman's compilation of his own figures and those of Dahlberg, von Verschuer, and Hirsch, given in his book (1937), and from the quotations from the literature and the original data supplied by Wilson and Jones (1932) the following table has been compiled :

\begin{tabular}{lll|c|c|c|c}
\hline & & \multirow{2}{*}{$\begin{array}{c}\text { TOTAL NO. } \\
\text { TWINS }\end{array}$} & \multicolumn{3}{|c}{ PERCENT. LEFT } \\
\cline { 6 - 7 } & & & & & \\
\hline
\end{tabular}


Von Verschuer (1932) provides a mass of data on the occurrence of asymmetries in human twins, and comes to the conclusion that the distribution of the asymmetrical character between the two twins is a chance phenomenon. If the reversal of the asymmetrical feature is due to the process that Newman hypothecates, then one would expect the presence of one asymmetrical feature to show a high correlation with the presence of others. Von Verschuer has worked out a series of these correlation coefficients, all of which proved not to be statistically significant. The two following tables are quoted from him:

\begin{tabular}{|c|c|c|c|}
\hline & & \multicolumn{2}{|c|}{$\begin{array}{c}\text { CORRELATION COEFFICIENT BETWEEN } \\
\text { TWO ASYMMETRICAL FEATURES BY } \\
\text { INDIVIDUALS }\end{array}$} \\
\hline & & UNIOVULARS & BINUVULARS \\
\hline $\begin{array}{ccc}\text { Handedness and hand-folding } & . & \ldots \\
, " & \text {, arm crossing crown-whorl (direction). } \\
\#, & \text { ", crown-whorl (site) } \\
\text { Hand-folding and crown-whorl (direction) }\end{array}$ & $\begin{array}{l}\cdots \\
\cdots \\
\cdots \\
\cdots\end{array}$ & $\begin{array}{l}+0 \cdot 16 \pm 0 \cdot 12 \\
-0 \cdot 18 \pm 0 \cdot 12 \\
-0 \cdot 18 \pm 0 \cdot 12 \\
-0 \cdot 13 \pm 0 \cdot 15 \\
+0 \cdot 16 \pm 0 \cdot 16\end{array}$ & $\begin{array}{l}+0 \cdot 05 \pm 0 \cdot 15 \\
-0.27 \pm 0 \cdot 15 \\
+0 \cdot 17 \pm 0 \cdot 14 \\
-0.07 \pm 0 \cdot 15 \\
+0.04 \pm 0.18\end{array}$ \\
\hline
\end{tabular}

\begin{tabular}{|c|c|c|c|}
\hline & & \multicolumn{2}{|c|}{$\begin{array}{c}\text { CORRELATION COEFFICIENT BETWEEN } \\
\text { CONCORDANCE (OR DISCORDANCE) OF } \\
\text { TWO ASYMMETRICAL FEATURES, BY } \\
\text { TWIN PAIRS }\end{array}$} \\
\hline & & UNIOVULARS & BINOVULARS \\
\hline $\begin{array}{ccc}\text { Handedness and hand-folding } & \ldots & \ldots \\
, " & \# \text { arm-crossing (direction) } & . . \\
\text { Hand-folding and crown-whorl (direction) }\end{array}$ & $\begin{array}{l}\cdots \\
\cdots \\
\cdots \\
\cdots\end{array}$ & $\begin{array}{r}+0.08 \pm 0.12 \\
-0.09 \pm 0.13 \\
-0.03 \pm 0.12 \\
0.00 \pm 0.13 \\
-0.08 \pm 0.16\end{array}$ & $\begin{array}{l}+0 \cdot 15 \pm 0 \cdot 15 \\
+0.03 \pm 0 \cdot 12 \\
+0 \cdot 07 \pm 0 \cdot 14 \\
-0 \cdot 05 \pm 0 \cdot 13 \\
+0 \cdot 11 \pm 0 \cdot 18\end{array}$ \\
\hline
\end{tabular}

It is to be regretted that von Verschuer does not state the number of twins on which these figures are based. The absence of any correlation between any two asymmetries, however treated, does, however, provide a strong argument against Newman's hypothesis. Newman himself states that he has found correlation between various asymmetrical features, such as palm-prints and dental irregularities with handedness or crown-whorl, but his data are hardly given in sufficient detail to permit of any judgement.

The matter must therefore be regarded as still open. A judgement is made more difficult by the paucity of information on the frequency of these asymmetrical characters among the children of single births. So far it seems that left-handedness alone shows a higher incidence in twins than in singletons, and that in twins it is not yet certain that there is a higher incidence in the monozygotic than in the dizygotic. The increased frequency of left-handedness in fraternal twins as compared to the general population, pace Newman, does suggest that left-handedness in both varieties of twins may have a common explanation. This common explanation would be sought in the twin-pregnancy itself, a theory which would be quite in accordance with von Verschuer's failure 
to find any correlation between the presence of one asymmetry and the presence of another. The matter, as Newman rightly points out, is not thereby disposed of. An individual in whom a partial reversal of asymmetry has occurred, e.g. an ambidextrous person, is not the same as one in whom it has not occurred, even where other qualities, such as psychological ones, are considered. If partial reversals of the functional asymmetry of the brain, from whatever cause, are of common occurrence in twins, they would be of fundamental importance for psychiatry. What their importance would be, however, would be a most difficult matter to assess. Whether this phenomenon of asymmetry reversal, if it occurs, be regarded as of environmental origin or not, there seems to be little sound evidence for Dahlberg's view that it can be accompanied by differences in the distribution of the germ-plasm. There is no more reason to suppose that two monozygotic twins, even showing discordance in asymmetrical features, are of different genotypic constitution than to suppose that the two sides of the body are different in this respect. As long as we are dealing with symmetrical characters or qualities expressed by the individual as a whole, as is mostly the case in psychiatry, we are justified in neglecting the theoretical possibility of inequalities in twin pairs from this cause.

So much for the theoretical basis of twin research. In a comprehensive review of its application in psychiatry in 1930 Luxenburger points out that work on twins may be classified into three kinds. There is the single-case report, the collection of a small or large number of cases in an unsystematic way, and the serial investigation in which all types of twins fulfilling certain conditions are examined, regardless of their ovularity, concordance, or discordance, etc. The great wealth of the literature is made up of work of the first kind, and, as Luxenburger has shown, it is for statistical purposes very largely useless. For it has been convincingly shown that when such reports of single cases are collected together and analysed they give no true picture of the twin material as provided by nature. They represent a selection of a particular type of case, the selection being in the first place for concordance. It is where both twins have suffered from schizophrenia, for instance, that the interest of the clinician has been aroused. These collections of single cases from the literature contain a quite undue proportion of concordant and of monozygotic twins, and even in the concordant cases there seems to be an undue selection for a far-reaching concordance down to the finest clinical details.

Luxenburger (1930b) provides a table compiled from the literature up to 1930, from which the following is extracted :

\begin{tabular}{|c|c|c|c|c|c|c|c|c|c|c|c|}
\hline & & & & \multicolumn{2}{|c|}{ UNIOVULAR } & \multicolumn{2}{|c|}{ BINOVULAR } & \multicolumn{2}{|c|}{ UNCERTAIN } & \multicolumn{2}{|c|}{ TOTAL } \\
\hline & & & & CON. & DIS. & CON. & DIS. & CON. & DIS. & CON. & DIS. \\
\hline Schizophrenia & & $\ldots$ & .. & 31 & 3 & 3 & 5 & 9 & 2 & 43 & 10 \\
\hline Manic-depressive & . & $\ldots$ & $\ldots$ & 24 & 1 & 1 & 1 & 2 & 2 & 27 & 4 \\
\hline Epilepsy ... & . & . & . & 5 & 2 & 一 & - & 2 & 1 & 7 & 3 \\
\hline Psychopathic & perso & & and & & & & & & & & \\
\hline hysteria .. & $\ldots$ & . & . & 4 & 5 & - & - & 1 & - & 5 & 5 \\
\hline Oligophrenia & . & . & $\ldots$ & 10 & 1 & 一 & 4 & 4 & 2 & 14 & 7 \\
\hline Mongolism .. & . & $\cdots$ & $\cdots$ & - & $1 ?$ & - & 22 & 7 & 16 & 7 & 39 \\
\hline
\end{tabular}


It will be noted that, when mongols are omitted, over two-thirds of the reported twins are uniovular. The normal expectation would be to find about one-third uniovular. As exemplifying the differing value of the three types of work on twins, he provides the following striking table, showing the comparative results from $(a)$ collection of cases from the literature ; $(b)$ cases collected by circulars sent to doctors, institutions, etc.; and $(c)$ the systematic collection of an uninterrupted series :

Frequency of Concordance and Discordance in Groups of Twins gathered by Different Methods, Per cent.

\begin{tabular}{|c|c|c|c|c|c|c|c|c|c|}
\hline & & \multicolumn{2}{|c|}{ UNIOVULAR } & \multicolumn{2}{|c|}{ BINOVULAR } & \multicolumn{2}{|c|}{ UNCERTAIN } & \multicolumn{2}{|c|}{ TOTAL } \\
\hline & & $\begin{array}{c}\text { CON. } \\
\%\end{array}$ & $\begin{array}{l}\text { DIS. } \\
\%\end{array}$ & $\begin{array}{c}\text { CON. } \\
\%\end{array}$ & $\begin{array}{l}\text { DIS. } \\
\%\end{array}$ & $\begin{array}{c}\text { CON. } \\
\%\end{array}$ & $\begin{array}{l}\text { DIS. } \\
\% \%\end{array}$ & $\begin{array}{c}\text { CON. } \\
\%\end{array}$ & $\begin{array}{l}\text { DIS. } \\
\%\end{array}$ \\
\hline (a) Cases from literature .. & . & 91 & $\dot{9}$ & 40 & 60 & 72 & 28 & 82 & 18 \\
\hline (b) Unsystematic collection & . & 92 & 8 & - & 100 & 53 & 47 & 56 & 44 \\
\hline (c) Systematic collection & . & 64 & 36 & - & 100 & 11 & 89 & 19 & 81 \\
\hline
\end{tabular}

As Luxenburger says, the necessity for systematic unbiassed collections of twins may, on these data, be regarded as proven. Statistical analysis of the frequency of twinning in a clinical group, the extent of concordance in monozygotic twins as to clinical picture, onset, course, and outcome, is therefore impossible on the basis of such investigations. For the same reason uncontrolled collections, without guarantees against special and undesirable selection, are also unreliable. The last class of statistically unobjectionable serial investigations, securing a representative collection of twins, concordant and discordant, monozygotic and dizygotic, were in 1930 of great rarity ; and even to-day there are not many of them. It is largely due to Luxenburger that the merits of this type of investigation are now recognized and that psychiatrists have made as much use of the method as they have. The method, as he demands it should be carried out, is to start from a particular group of patients, selected on grounds of their being in particular hospitals at a particular time or otherwise having fixed and definite limitations of time and space, and by inquiries made at registry offices to discover all the twin births, irrespective of whether the twin survived or died, became subsequently ill or remained well, and to subject the whole of the material to an exhaustive examination. In this way a series is obtained which is without gaps and is representative : (1) in respect of the frequency of twins among the bearers of the character under investigation ; (2) in respect of the comparative frequency of like and oppositesexed pairs, of monozygous and dizygous pairs, of concordance and discordance. Information on all these points may be of the greatest importance for any judgement to be reached on the presence, importance, and nature of hereditary factors. Even this type of investigation, as Luxenburger has said, is not without statistical source of error ; for by its means those twins are never discovered where, in spite of the presence of the hereditary factor, neither twin has developed the illness, abnormality, or character investigated. This source of 
error is unavoidable, and must limit the value of all twin investigations. It is, however, often not feasible to approach Luxenburger's moderate ideal. It is in England, for instance, impossible to ascertain the fact of twinning from birth registers. Furthermore, for the final figures to be sound it would be necessary to make sure that the whole of the original material out of which the twins were selected is uniform-that, for instance, all possibilities of incorrect diagnosis have been eliminated. When a large twin material is being collected this is obviously not humanly possible. Most twin investigators will, therefore, have to content themselves with something less than what would be theoretically desirable. If the method of ascertainment of the twins is such that there is no likelihood of either uniovular or binovular, concordant or discordant twins being more largely represented in the final material than their proportional representation in nature, this is as much as can be demanded. The necessity of undiscriminating attention to all the material extends itself throughout the whole of the work, however, and it is necessary that the twins should not only be ascertained but also worked up with equal care, regardless of whether they are monozygotic or dizygotic, concordant or discordant. Furthermore, the reliability of any such investigation demands the satisfactory diagnosis of ovularity.

This is not to assert that all case reports of single cases are without value. A particular character may be of such rarity that its occurrence in a pair of twins is an event of importance and worthy of record. In such cases clinicians should be aware of the fact that all twins, monozygotic or dizygotic, concordant or discordant, are of importance. It is, however, obviously better that such twins should be ascertained by an automatic method which does not depend for its certainty on the interest of the clinician. All hospitals where any research work is done at all should make inquiries as to twinship about all their patients as a matter of ordinary routine, so that when an interested investigator appears he may have a chance of following up all cases showing a particular syndrome.

\section{Twin Research in Mental Defect}

In attempting a summary of the results obtained by twin investigations in psychiatry, and taking at first the subject of mental defect, the large number of case reports that have been made on cases of mongolism occurring in twins provide an elegant example of the weakness of the methods used hitherto. In spite of the rarity of the condition, it has aroused so much clinical interest that Rosanoff in 1934 (1934a) was able to collect 59 cases from the literature, and his collection was by no means complete. To these 59 cases he was able to add 5 new pairs of his own. Of these 64 pairs, in five the sex of the twins is not stated. It is difficult to imagine why a clinician can have left out such an important point in his report. A further 23 pairs were of opposite sex. This is about the number one would expect in a random selection; so mongolism forms the only exception to the rule stated by Luxenburger to the effect that cases from the literature represent a selection for uniovularity. Rosanoff states that 
eight pairs were monozygotic and all concordant. All the same-sexed pairs held to be dizygotic and all the opposite-sexed pairs were discordant in respect of mongolism. These findings might by themselves be interpreted as indicating that a hereditary factor played a major rôle in the ætiology. Rosanoff, however, agrees with the majority of other workers in thinking that the condition is not hereditary, and that the twin findings do not stand in contradiction to this belief. Family investigations do not disclose an increased frequency of mongolism among the sibs of mongols. The most widely held theory of the causation of mongolism is that the condition is due to faulty implantation of the ovum in an abnormal uterine mucosa. Monozygotic twins with closely neighbouring implantation sites and with a common placenta would naturally be likely to be concordant in regard to a character caused by deficient or abnormal nutrition consequent on the location of the placenta. Rosanoff's theory is that the condition is caused by injury to the ovum on ovulation, the injury being brought about by scars produced in the ovary by previous ovulations. The frequency of mongolism would on that theory naturally increase with increasing age of the mother, as has repeatedly been shown to be the case. One of the cases which Rosanoff has not collected from the literature is Siegert's case (1922, quoted by Siemens 1924) of discordant monozygotic twins. Were the uniovularity of Siegert's twins established (no evidence beyond a statement is provided), it would be a direct proof of the incorrectness of Rosanoff's theory, which obviously demands that all monozygotic twins without exception should be concordant.

The fact is that no definite statement can be made about the incidence of mongolism in monozygotic and dizygotic twins from cases collected from the literature, as Rosanoff has collected them. The diagnosis of ovularity is not satisfactorily carried out in one of them. Nevertheless, the example of mongolism provides a lesson in the necessity of caution in the interpretation of concordance-discordance differences in monozygotic and dizygotic twins as a direct measure of the relative prepotence of heredity. In any case where a particular character may be the result of intra-uterine processes or of the process.of twinning, it is clear that the results of researches into twins must be interpreted with especial caution.

Apart from mongolism, case reports on the occurrence of special forms of mental defect in twins are few and unimportant. Dorff (1934) has reported a case of cretinism occurring in one of binovular twins; in uniovular twins Wilson and Wolfsohn (1929) have reported cerebral deplegia with mental defect and congenital nuclear ophthalmoplegia with mental defect, von Engerth (1933) tower skull, Fabing (1934) epiloia, Jenkins and Glickman (1934) birth injury (one only affected). In most cases a selection of the appropriate literature is given. In Fabing's case, which appears to be unique, no data are given relevant to the diagnosis of ovularity. In both his and von Engerth's case there are interesting data regarding mirror-imaging in pathological features. Von Engerth's case is beautifully worked up from the biometric aspect. A not uninteresting case is reported by Schmitz-Lückger (1932), who observed mental defect of about the same degree and with many clinical similarities in a pair of 
opposite-sexed twins, and suggests it was due to the contraceptive employed by the parents, which had not prevented the occurrence, but had damaged the result of conception.

Of the more usual types of mental defect a number of single cases occurring in twins have been reported, which it is not worth while to detail, as more valuable material is available. Both Smith (1929, 1930) and Rosanoff (1931, 1934) have made fairly systematic investigations in this field.

Rosanoff (1931) has published his results with mentally defective twins with a brevity that robs his paper of much value. He gives no account of the methods of selection, no account of the cases from a clinical point of view, no account of the methods used for the diagnosis of ovularity, nor is there any statement of any quantitative measurement of the degree of defect. The body of the paper is given over to a discussion of a theory of the method of inheritance which will be dealt with later. From the brief and incomplete analysis he gives of his material the following table can be constructed:

\begin{tabular}{|c|c|c|c|c|c|}
\hline & & & CONCORDANT & DISCORDANT & TOTAL \\
\hline Monozygotic & . & . & 33 & 2 & 35 pairs \\
\hline Dizygotic, same-sexed & $\cdots$ & . & 21 & 12 & 33 \\
\hline Dizygotic, opposite-sexed & . & . & 11 & 16 & 27 \\
\hline
\end{tabular}

Of the 16 discordant opposite-sexed pairs, the male was affected in 11 cases, the female in five. In all there were 91 mentally defective in 101 males, 69 mentally defective in 89 females. Rosanoff attempts to interpret his findings as reconcilable with a dimeric inheritance of mental defect, the factors being in both cases recessive, one autosomal, the other located in the X-chromosome. $\mathrm{He}$ finds support for this theory in the results of the family investigations of Goddard, which he has subjected to an analysis with this theory in view. In a later paper (1934) he reports the findings in a further 65 (making in all 81) pairs of opposite-sexed twins. Among these he found 34 pairs where both twins were mentally defective, 31 where the male alone was affected, 16 where the female alone was affected. He further reports the findings in 233 pairs of opposite-sexed twins, of normal or superior intelligence (I.Q. 76-161), and found that the girls tended to have a higher intelligence than the boys. He further examined the intelligence scores of the parents of 100 of these twins and found that the fathers had higher I.Qs. than the mothers in 57 of the 100 cases. The sex-distribution of higher I.Q. in the parents had no correlation with the sexdistribution of higher I.Q. among the twins-a fact that speaks strongly against Rosanoff's theory, though he does not treat it as such. On this basis Rosanoff and his co-workers build up a theory of the greater vulnerability of the male fœtus and sex-linked recessive inheritance as independent causes of the higher intelligence among the girls. A full analysis of Rosanoff's figures and his argument would not repay itself, but there is one important possibility to be pointed out. Rosanoff nowhere states what the ages of his twins were. It 
seems extremely probable that he was dealing with children, as he speaks everywhere of boys and girls. Now it is a well-known phenomenon that in the curves of growth of intelligence with age of boys and girls, the curve is steeper in the case of girls than boys, and that in consequence the girls reach maturity in intelligence before the boys do. If this factor has not been taken into account by Rosanoff it would make just such a systematic difference between male and female twins as he observed.

Luxenburger, stimulated by Rosanoff's theory, has published (1932) an analysis of the material of Brugger and Lokay, which as it is not a twin-material, is not the immediate concern of this review. Nevertheless, the figures he supplies are of interest and importance. In the families of 209 propositi he found the frequency of mental defect among children classified according to the constitution of their parents to be as follows :

\begin{tabular}{|c|c|c|c|c|c|}
\hline & & & & SONS & DAUGHTERS \\
\hline Both parents normal & . & . & . & $0.212 \pm 0.085$ & $0.097 \pm 0.020$ \\
\hline Father defective, mother normal & . & . & .. & $0.404 \pm 0.068$ & $0.577 \pm 0.097$ \\
\hline Father normal, mother defective & . & . & . & $0.538 \pm 0.098$ & $0.423 \pm 0.068$ \\
\hline Both parents defective & . & . & .. & $0.925 \pm 0.041$ & $0.892 \pm 0.051$ \\
\hline
\end{tabular}

Luxbenburger analyses the expectations of what these proportions would be on the theories (1) of simple autosomal recessive inheritance, (2) of simple recessive sex-linked inheritance, (3) of both methods of inheritance occurring in a mixed population, (4) of dimeric recessive autosomal and sex-linked inheritance (Rosanoff). He finds that the last theory provides the best explanation of the facts. Luxenburger's mathematics are not above reproach. $\mathrm{He}$ has, for instance, made no allowance for the comparative frequencies of the different types of crossings which would be productive of defectives. The mathematics of this problem are certainly more complicated than Luxenburger represents them, and would be worth the attention of a mathematical specialist. I think it would be found that Rosanoff's theory provides an inadequate explanation of the empirically found figures, and it seems to me likely that it would involve a greater relative frequency of mental defect in males as compared with females than is actually found. Rosanoff is himself aware of the inadequacy of his theory, and brings in the supplementary hypothesis of the greater vulnerability of the male fotus. Luxenburger also does not suppose that this method of dimeric inheritance would be applicable to all cases of hereditary mental defect, but thinks that other methods of inheritance also play a part, if only a minor one. The chief criticism of the work of these two authors must be that it represents an over-simplification of the problem. Human beings are not simply to be divided into normal and defective. Any theory of the inheritance of mental defect must provide an explanation of the curve of normal distribution of intelligence found in both males and females. It seems to me that the only two theories that will simply explain this phenomenon are : (1) that there are 
a large number of factors for mental defect, which are of different frequency in the population, and each produce mental defect of different degrees; or (2) that there are a large number of factors for intelligence, any number of which may be present in a single individual, the effect of any one of which will be to enhance the action of any of the others-that is, the more of these factors - anyone has, the more intelligent he will be, the less the less. The two theories are not mutually exclusive and there is much to suggest that both have some truth. But even that represents an over-simplification, as among other things the environment must play a rôle.

The effect of the environment on intelligence and character has been the subject of an elegant and painstaking investigation of Newman, Freeman, and Holzinger (1937), an investigation which will probably remain unique. It must be briefly referred to, as it is not principally concerned with mental defect. The unique part of the work consists in the collection of 19 pairs of monozygotic twins who had been separated in early life and brought up in different environments. The authors were able to show that the intelligence, as estimated by standard tests, is subject to greater variation with varying environment than is commonly supposed. The same was true of character-traits, as estimated by other tests ; but this part of their work is less satisfactory, owing to the greater difficulty in interpreting the meaning of such tests. The result of their work is to throw into relief the limitations of twin work and to illuminate the fundamental difficulty of stating what the problem is, which is involved in the often formulated antithesis, heredity vs. environment. It is clear that if one were to take two individuals of like innate ability, and subject one from infancy to adult life to a stimulating and well-balanced education, and to keep the other from education of any sort whatever, the final result would be very different in the two cases. This is what the above-named authors have shown, in a less extreme case, to be true. Under the widest range of environmental circumstance they found the extreme range of variation in intelligence quotient to be 24 per cent. In this case the variation was from 8 points below to 16 points above the normal value of 100 per cent. It is not admissible to argue from this that at lower or higher levels of intelligence a comparable change in the environment would produce an equal change in the test-intelligence. Both environment and heredity in the individual set limits to the range of variation in intelligence, of which the lower limit is nil. If the environment is depressing, an improvement in it may be expected to produce a marked improvement in the intelligence. If, however, it is already favourable, a comparable variability cannot be expected. That quite large changes in the environment do not as a rule produce large changes in the I.Q. is shown by Holzinger's calculations that the mean difference in I.Q. in these 19 twins was little more than 8 points. That it was found to be as much as this will be a matter for surprise for some.

The investigation of Newman, Freeman, and Holzinger was principally concerned with the effect of the post-natal environment. To the prenatal environment and to the various environmental influences brought to bear at the time of birth, a probably much larger rôle is to be ascribed. The effect of 
birth-trauma in producing mental defect has not yet been satisfactorily investigated. Brander (1935) has drawn attention to this, and has criticized especially the work of Smith, still to be discussed, as taking insufficient account of birth-trauma as a cause of defect, especially in concordant twins. In his own series of 10 mentally defective twin-pairs birth anomalies had played a considerable rôle, and the twin with the lower I.Q. had in every case been . subjected to their influence. He emphasized especially the importance of minor degrees of birth-trauma in producing the less gross degrees of mental retardation. There seems to be much justice in his criticism; and there is no reason to think that birth trauma, like the environmental factors responsible for mongolism, may not produce mental defect in both of a pair of uniovular twins.

Smith gives an account of his investigations in two papers. An account at length is given in the Danish language (1929), and is not available to the reviewer. A shortened account is also given in German (1930), and appears to contain the more essential facts. In the course of the registration of all the mental defectives in Denmark, Smith ascertained all the multiple births among the first 6,700 mental defectives registered. In 67 pairs of twins full details were available. Of these 35 pairs were of opposite sex. A careful attempt was made to establish the ovularity of all the same-sexed pairs, and though this was not possible with certainty in every case (for instance where the twin partner was already dead), there is no reason to think that errors of ovularity diagnosis are a large source of error in his results. He found in all 50 pairs of binovular twins, of whom four were concordant in respect of mental deficiency. In one case no decision could be reached as to ovularity. In three cases uniovularity was regarded as probable : all of these were concordant. Thirteen pairs were regarded as certainly uniovular, of whom 11 pairs were concordant, two discordant. The proportion of concordance in uniovular pairs (11/13 $=84.6$ per cent.) compared to that in binovular pairs ( 8 per cent.) speaks, as Smith remarks, strongly for the hereditary determination of the majority of cases of mental defect. Smith's cases were all quite ordinary cases of mental defect, with or without history of fits, with or without neurological abnormalities. There were no cases of the rarer and special forms of mental defect. He was unable to find a clinical picture that was characteristic for a hereditary or for an acquired form of the condition. His most interesting finding is that a number of the concordant uniovular pairs showed various neurological abnormalities. In pair 109. both twins had a left-sided spastic hemiplegia, both had convulsions as children; one of the pair got progressively worse and died at the age of 22 ; the other improved, though neurological signs remained. Both twins of pair 115 showed disturbance of speech, with defective articulation, both were somewhat deaf, one showed a positive Babinski. In another three pairs (perhaps four) both twins had convulsions, and one of one pair died in status epilepticus. This conformity of neurological picture Smith is inclined to interpret as suggesting that even those cases of mental defect which show an abnormal neurological picture may be due to hereditary and not to any exogenous cause. The possibility must be conceded, but the evidence is 
not conclusive. Other explanations cannot be excluded, as in the case of mongolism.

Smith's two discordant uniovular pairs both show an obviously exogenous disorder. In pair 120 the affected twin had fits from the third day after birth, recurring at intervals since. The left side of the body became with further growth markedly underdeveloped, and he died in a state of idiocy at eight; his brother was normal. This would appear to be a case of birth trauma. In case 121 (triplets), the affected twin and his sister had a severe exanthematous illness at the age of three months, by which the healthy brother remained unaffected.

As regards the degree of defect, Smith does not provide very detailed information in his German paper ; but from what facts he does give it is clear that there were perceptible though not very large differences in this respect Only in one pair (116) is the difference at all a marked one. Characterological differences were also noted in the concordant twins. One gets the impression from the work that an inborn tendency to mental defect manifests itself in a high proportion of the cases where it is present, and generally to its full effect. In other words, the gene or genes responsible show, in the language of genetics, high values for manifestation rate, expressivity, and specificity. This is not to say that environmental factors are not important. There may be cases of mental defect largely determined by heredity where the environment is largely without power of modification, and others caused solely by the environment (e.g birth trauma) where there has been no hereditary predisposition.

Working on Smith's material, Luxenburger has attempted to obtain an actual value for the manifestation rate of the hereditary factors responsible for mental defect. By manifestation rate is meant the average percentage of cases where the genotypic factors are present in which they show themselves phenotypically.

Luxenburger provides a formula

$$
\mathbf{M}=\frac{m_{g}-p v y^{\prime}}{(z-2 p) y^{\prime}}
$$

in which $\mathrm{M}$ represents the manifestation rate, $m_{g}$ the number of concordant twins among the like-sexed pairs, $v$ the empirically found expectation of sibs to be affected similarly to the propositus (in this case with mental defect), $y^{\prime}$ the expectation of a twin reaching the average age of the material investigated and $z$ the total number of twin proposity. This formula is for use on a total twin material, including all cases that died in infancy, and can only be applied to material gathered by a method of selection where such factors as age, sex concordance, etc., have no selective effect. Its great convenience is that it avoids the determination of ovularity altogether. Its weakness lies in the fact that the factors $v$ and $y^{\prime}$ are themselves subject to large errors. From Smith's figures Luxenburger calculates the " expected figure" for the manifestation rate of the genes of mental defect as 0.835 , and compares this with the " observed figure of 0.846 (the number of concordant uniovular twins divided by the total number of uniovular twins, here 11/13). Luxenburger points out that the agreement is good. It is, however, without significance. 
The " manifestation rate" of an inherited disposition is a term derived from animal genetics. It signifies that where the inherited tendency towards the development of a certain character is present it will manifest itself in a certain proportion of cases. In the remainder it will remain inhibited. The inhibition may be either by the action of other inherited factors or by the presence of an unsuitable environment. If the inhibition is solely by reason of other inherited factors, it will take place, if at all, in both of a pair of twins, which will then entirely escape observation. The calculation of the manifestation rate from concordance-discordance figures from twin studies gives only an expression for the effect of the environment. The environment may, however, be of such a quality that the character is produced (or imitated) without the inherited tendency being present at all. This is probably the case with Smith's two discordant pairs, where there are certainly no grounds for the assumption that there was a hereditary disposition to mental defect present in both twins which showed itself in only one. These two cases would more properly have been excluded from the calculation, and the "observed" manifestation rate is in Smith's cases apparently $1 \cdot 0$.

Luxenburger, however, in his analysis of Smith's results is concerned with a particular point. He quotes the results of Brugger and Lokay, who investigated the frequency of mental defect among the sibs of defectives, and found it to be $0 \cdot 13$ to $0 \cdot 18$. Both figures are well behind the expected $0 \cdot 25$ on the assumption of simple recessive inheritance. Luxenburger is concerned to show that this discrepancy is not due to deficient manifestation of the inherited factor. It is clear that a manifestation rate of 0.835 or 0.846 or 1.0 will not explain the total discrepancy, but at most a part of it. Luxenburger seems not to have been aware at this time of the possible additional disturbing effect of other inherited factors than the specific ones (factors conveniently classed as the " genotypic milieu "), but only to have reckoned with possible environmental interference. As Luxenburger has himself subsequently pointed out, the effect of the genotypic milieu is most conveniently to be measured together with the effect of the environment (when certain assumptions are made as to the mode of inheritance) by discovering the frequency of a character among the children of parents, both of which show it. From Luxenburgers figures, previously quoted, it appears that the incidence of mental defect among the children of two defective parents is about $0 \cdot 9$.

Luxenburger next considers the possible influence of lethal effects of the genes concerned. Obviously if a particular gene were to have a lethal effect the number of its carriers in a given population would be reduced and in families known to carry the gene the number of those giving evidence of its presence would be below the expected value. Even if the lethal effect were only exhibited in a percentage of cases, this would still be the case. Obviously the genes for mental defect are not absolutely lethal, because then there would be no subjects of mental defect that would survive. Luxenburger attempts to test the possibility of a lethal effect showing itself in a proportion of cases by calculating the relative and absolute frequency of uniovular and binovular pairs in Smith's material. 
The method is based on a statement of Weinberg's to the effect that among the bearers of a character which involves an increased prenatal mortality, a relatively reduced percentage of binovular twins is to be expected. Luxenburger calculates that the percentage of twins in Smith's material $(122$ in 6,689) corresponds to average expectation and that the opposite-sexed twins (i.e. certainly dizygotic twins) are neither more nor less frequent than could be expected. He deduces from this that the fact of twinning as such does not predispose to mental defect, and that there is no evidence of any lethal effect exercised by the genes of mental defect.

These conclusions may be true, but the reasoning does not seem to be altogether sound, and there are reasons to be sceptical. Twin conception is known to predispose to increased prenatal mortality, twin birth to birth injury, and birth injury to mental defect and to reduced viability. Luxenburger seems to have made no direct comparison of the duration of life of the twin partners in Smith's material with the life tables of the general Danish population, a population of defectives, or with a population of normal twins. Facts gained from such comparisons would be more valuable than the somewhat indirect evidence supplied.

Luxenburger's argument, that the normal distribution of uniovular and binovular twins in Smith's material is against the assumption of any lethal effect, rests entirely on the validity of Weinberg's statement that a lethal effect would show itself in a reduced number of binovular twins. Luxenburger does not give a reference to the particular work of Weinberg's in which this statement occurs and I am unable to trace it. The statement itself, though proceeding from a statistical authority, seems to me of questionable truth.

One might approach the problem as follows :

Taking a group of crossings which produce the character under discussion, let :

$a=$ the number of uniovular twin pairs born,

$b=$ the number of binovular twin pairs born,

$v=$ the frequency of the character in the children of these crossings.

Then there will be :

$$
\begin{aligned}
& a v \\
& a(1-v) \quad \text { uniovular pairs with the character, } \\
& b v^{2} \quad \text { binovular pairs without the character, } \\
& 2 b v(1-v) \text { binovular discordant pairs, } \\
& b(1-v)^{2} \text { binovular pairs without the character. }
\end{aligned}
$$

Starting from twin propositi one will discover (by Weinberg's " Probandenmethode," used in all the German calculations) :

$2 a v \quad$ concordant uniovular pairs,

$2 b v^{2} \quad$ concordant binovular pairs,

$2 b v(1-v)$ discordant binovular pairs.

The relation of the uniovular twin pairs found to the binovular pairs found will be :

$$
\frac{2 a v}{2 b v^{2}+2 b v(1-v)}=\frac{a}{b} .
$$


Now let the character have a lethal effect $e$ which is exerted at random. Among the uniovular pairs who bear the character there now will be :

$a v(1-e)^{2}$ pairs where both twins survive,

2 ave $(1-e)$ pairs where one twin survives,

ave $e^{2} \quad$ pairs where neither twin survives.

Among the binovular twins there will be :

$b v^{2}(1-e)^{2} \quad$ concordant pairs where both twins survive,

$2 b v^{2} e(1-e) \quad$ concordant pairs where one twin survives,

$b v^{2} e^{2} \quad$ concordant pairs where neither twin survives,

$2 b v(1-v)(1-e)$ discordant pairs where both twins survive,

$2 b v(1-v) e$ discordant pairs where one twin survives.

Starting again from twin propositi one now will find :

$2 a v(1-e)^{2} \quad$ uniovular twin pairs, all concordant,

$2 b v^{2}(1-e)^{2} \quad$ binovular twin pairs, concordant,

$2 b v(1-v)(1-e)$ binovular pairs, discordant.

and the relation of uniovular to binovular twin pairs found will be

$$
\frac{2 a v(1-e)^{2}}{2 b v^{2}(1-e)^{2}+2 b v(1-v)(1-e)}=\frac{a}{b} \cdot \frac{1-e}{1-v e} .
$$

But as $v$ and $e$ are by hypothesis both positive fractions, $\frac{1-e}{1-v e}$ must be less than 1. This resolves itself to a statement that under the conditions laid down above, the lethal effect of a hereditary factor would show itself in a larger and not a smaller proportion of dizygotic twins in a total twin material.

The fundamental assumption in the above argument is that the lethal effect is exhibited in a proportion of cases distributed at random. If the lethal effect were dependent for its manifestation on favourable environmental circumstances, this might well be the case. If, however, the lethal effect were dependent on a favourable genotypic milieu, the result would be different.

Let us suppose that the character exhibits its lethal effect only where are a considerable number of certain other common genes also present. These other genes are only found all together in a proportion $e$ of cases. Now the circumstances among the binovular twins will remain as in the example worked out above ; but among the uniovular twins the lethal affect will show itself in a proportion $e$ of pairs, in all of which both members of the pair will be affected. Starting again from twin propositi, the number of monozygotic twin pairs found will now be no longer $2 a v(1-e)^{2}$, but $2 a v(1-e)$; and the relation of uniovular to binovular twins found will be no longer $\frac{a}{b} \cdot \frac{1-e}{1-v e}$ but $\bar{b} \cdot \frac{1}{1-v e}$. In this case the proportion of dizygotic twins found will be unduly low, as Weinberg is said to have stated.

But we do not know whether this purely hypothetical lethal effect is exhibited in accordance with one or other or both of the possibilities outlined above. It is therefore not admissible to argue from a normal distribution of uniovular and binovular twins that no lethal effect of the genes concerned is present. The 
matter is not of purely theoretical interest, as it might appear, for in the twin work on epilepsy we shall meet with it again and find far-reaching conclusions based on arguments similar to Luxenburger's.

If we attempt a summary of what twin work has added to our knowledge of the inheritance of mental defect we may say that its findings are in conformity with those supplied by family investigations, and indicate that hereditary factors are of great importance, though certainly not the only ones concerned in the production of the syndrome. Much further investigation is required, and not least in the rarer and special forms of mental defect. The systematic ascertainment of all twins in institutions for mental defectives would be likely to be productive of a very valuable material for research.

\section{REFERENCES}

Brander, T. (1935). Mschr. Kinderheilk., 63, 276.

Conrad, K. (1937). Fortschr. Neurol. Psychiat., 9, 197.

Curtius, F. (1930). Arch. Gynäk., 140, 361.

Curtius, F., and Verschuer, O. v. (1932). Arch. Rass. u. GesBiol., 26, 361.

Dahlberg, G. (1926). " "Twin Births and Twins from a Hereditary Point of View." Stockholm.

Dorff, G. B. (1934). Amer. J. Dis. Child., 48, 1,316.

Engerth, G. v. (1933). Z. ges. Neurol. Psychiat., 148, 670.

Fabing, H. (1934). Brain, 57, 227.

Jenkins, R. L., and Glickman, E. (1934). Amer. J. Dis. Child., 48, 130.

Lange, J. (1929). Allg. Z. Psychiat., 90, 122.

Lassen, M. T. (1931). Arch. Gynäk., 147, 48.

Lenz, F. (1933). Arch. Rass. u. GesBiol., 27, 294 and 311.

Luxenburger, H. (1929). Fortschr. Neurol. Psychiat., $1,82$. - (1930a). Ibid., 2, 373.

(1930b). Zbl. ges. Neurol. Psychiat., 56, 145.

- (1931). Z. ges. Neurol. Psychiat., 135, 767.

- (1932a). Fortschr. Neurol. Psychiat., 4, 1 and 49.

(1932b). Z. ges. Neurol. Psychiat., 140, 320.

- (1932c). Z. indukt. Abstamm. u. VererbLehre, 61, 223.

(1933). Fortschr. Neurol. Psychiat., 5, 1.

(1935). Ibid., 7, 173.

Meyer, H. C. (1932). Arch. Rass. u. GesBiol., 26, 387.

Newman, H. H. (1923). "The Physiology of Twinning." Univ. Press, Chicago.

Newman, H. H., Freeman, F. N., and Holzinger, K. J. (1937). " Twins : a Study of Heredity and Environment." Univ. Press, Chicago.

Rosanoff, A. J. (1931). Amer. J. Psychiat., 11, 289.

Rosanoff, A. J., and Handy, L. M. (1934). Amer. J. Dis. Child., 48, 764.

Rosanoff, A. J., Handy, L. M., Rosanoff, I. A., and Inman-Kane, C. V. (1934). J. Nerv. Ment. Dis., 80, 125.

Schmitz-Lückger, J. (1932). Psychiat. neurol. Wschr., 34, 437.

Siegert, . . (1922). Contribution to discussion in Klin. Wschr., 1, 2,259.

Siemens, H. W. (1924). “ 'Die Zwillingspathologie.” Springer, Berlin. (1932). Z. indukt. Abstamm. u. VererbLehre, 61, 208.

Smith, J. C. (1929). Medd. Danm. Antrop., 3, 1 (quoted Smith 1930, Luxenburger 1931, q.v. -not verified).

(1930). Z. ges. Neurol. Psychiat., 125, 678.

_- (1931). Acta Psychiat., Kbh., 6, 79. 
Thompson, O. (1929). Quoted Smith (1931), q.v.

Verschuer, O. v. (1925). Münch. med. Wschr., 72, 184.

- (1927). Ergebn. inn. Med. Kinderheilk., 31, 35.

(1932). Z. indukt. Abstamm. u. VererbLehre, 61, 147. (1933). Arch. Gynäk., 156, 362.

Wilson, S. A. K., and Wolfsohn, J. M. (1929). Arch. Neurol. Psychiat., 21, 477.

Wilson, P. T., and Jones, H. E. (1932). Genetics, 17, 560. 